\section{Gastrojejunocolic fistula as a cause of hypo- albuminemia and bilateral leg edema}

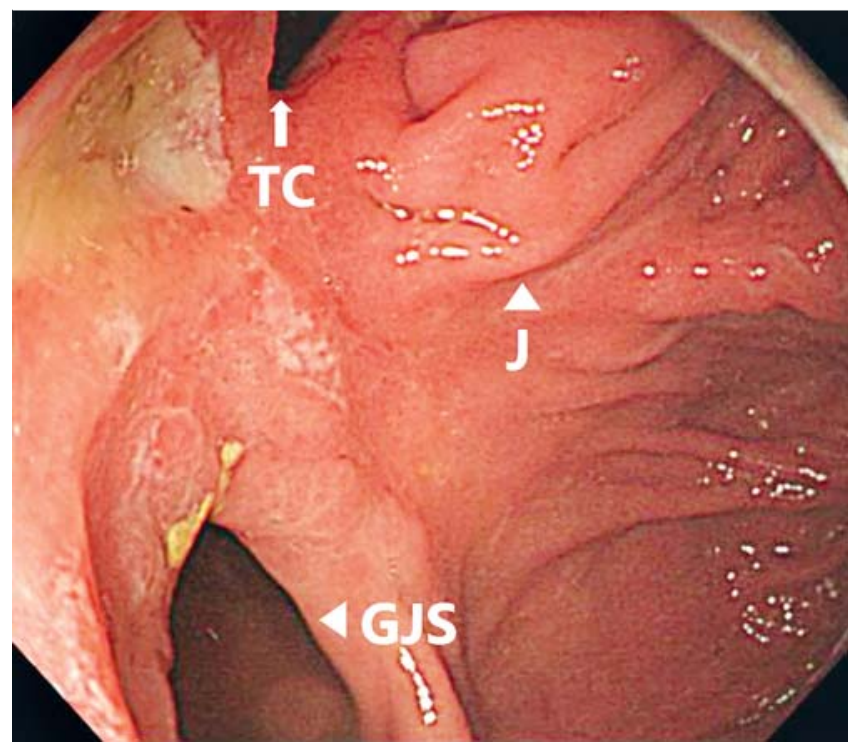

Fig. 1 Colonoscopy reveals two openings of a gastrojejunocolic fistula. The two arrowheads indicate the fistula openings (J, jejunum; GJS, gastrojejunostomy site); TC, transverse colon (arrow).

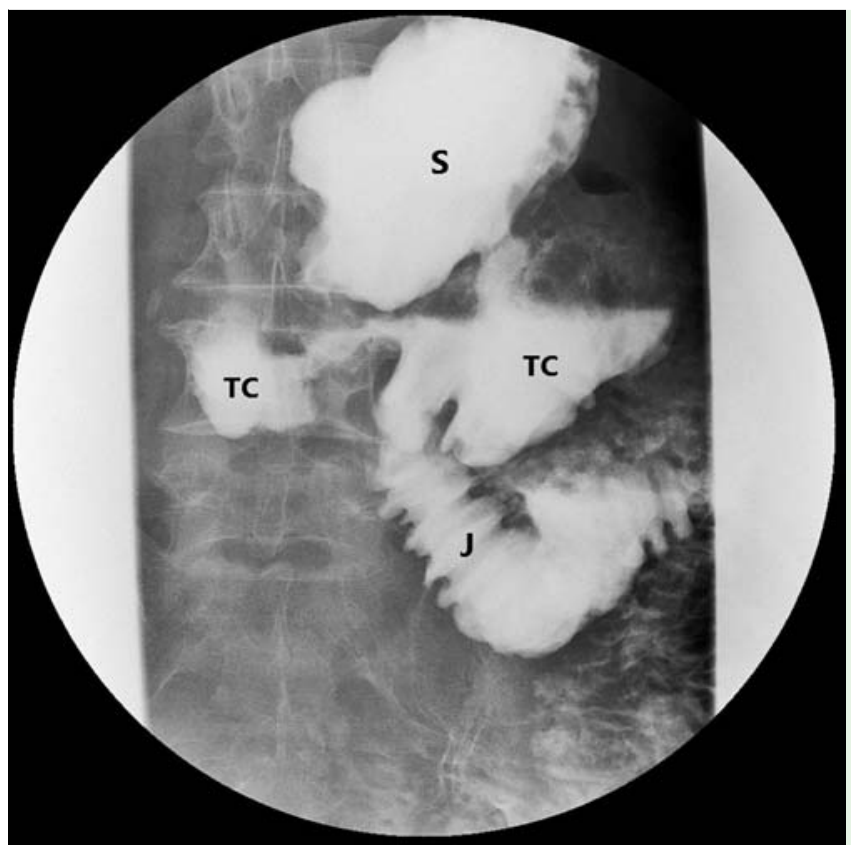

Fig. 2 Upper gastrointestinal series shows leakage of barium into the transverse colon from the stomach. S, stomach; J, jejunum; $\mathrm{TC}$, transverse colon.

A 49-year-old Korean man was admitted to our hospital on 15 November 2013 because of diarrhea, a body weight loss of $10 \mathrm{~kg}$ over 2 months, and a 1-month history of edema in both legs. He had undergone gastrectomy for gastric perforation after drinking agricultural chemicals in 2001, and in 2008 had also received a bypass gastrojejunostomy to treat pyloric obstruction resulting from recurrent gastric ulcers. Since then, annual upper endoscopy examinations conducted at tively. Hemoglobin was $10.3 \mathrm{~g} / \mathrm{dL}$, but plasma levels of electrolytes, coagulation tests, and kidney and liver function were all normal. Doppler ultrasonography of both legs revealed no evidence of deep vein thrombosis. Upper endoscopic examination revealed reflux esophagitis and the previous gastrostomy site low in the posterior wall of the body, with marginal ulcers and jejunal ulcers. Rapid urease test was positive. Colonoscopic examination revealed edematous mucosal change in the ascending and descending colon, and two openings suggestive of fistula in the transverse colon ( $\bullet$ Fig. 1). Barium upper gastrointestinal series revealed a fistula between the jejunum and the transverse colon ( $\bullet$ Fig.2). Abdominal computed tomography (CT) visualized the fistula more clearly ( $\bullet$ Fig. 3 ).

The patient was diagnosed as having a gastrojejunocolic fistula that was causing hypoalbuminemia and edema in both legs. He underwent segmental resection of the transverse colon and reconstruction of the gastrojejunostomy. After the operation, the edema in both legs and hypoalbuminemia gradually improved, the diarrhea stopped, and body weight increased. Two weeks after discharge the patient attended the outpatient clinic of this hospital; his edema was gone and his albumin level was $3.7 \mathrm{~g} / \mathrm{dL}$.

Gastrojejunocolic fistula is a rare complication of gastrojejunostomy [1]. The fistula results from perforation of marginal ulcers into the transverse colon [2]. Symptoms include diarrhea, weight loss, belching of fecal odors, vomiting, anorexia, and edema [3]. Anemia, leukocytosis, electrolyte imbalance, and hypoalbuminemia are common laboratory findings $[3,4]$. However, it is difficult to diagnose gastrojejunocolic fistula on the basis of these symptoms and laboratory findings, because there are many differential diagnoses. The most commonly used diagnostic tools are the barium upper gastrointestinal series and endoscopic examination. Abdominal CT is also used to identify the fistula and to exclude extra-abdominal disease. The treatment of choice of gastrojejunocolic fistula is surgery.

In our patient, the cause of the gastrojejunocolic fistula is thought to have been recurrent marginal ulcers resulting from persistent smoking or recurrent Helicobacter pylori infection after gastrojejunostomy. In patients with gastrojejunocolic fistula, the ingested food cannot pass in the physiologic order (stomachjejunum-ileum-colon), but can pass in a 


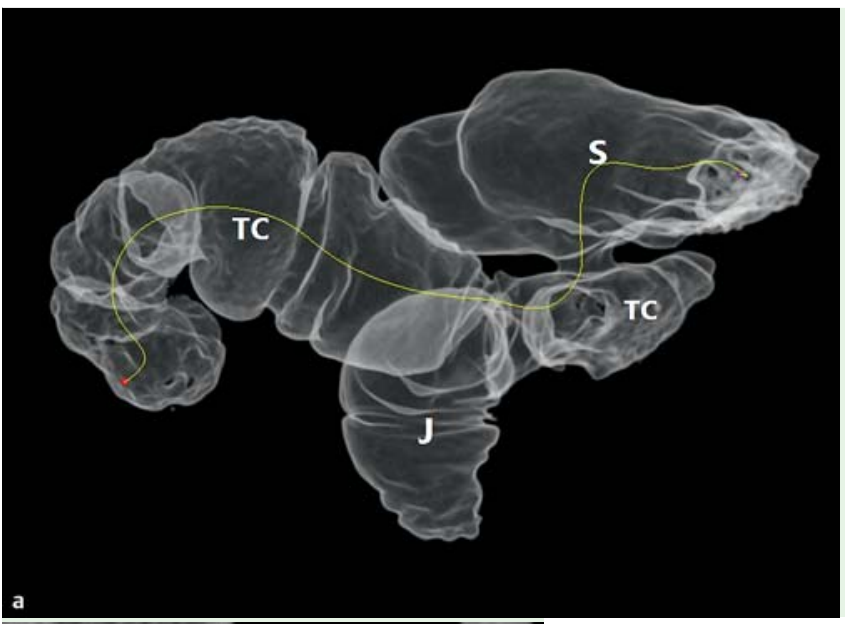

Fig. 3 Abdominal computed tomographic findings show a fistulous tract between jejunum and transverse colon: a 3D image, b 2D image.

S, stomach; J, jejunum; $\mathrm{TC}$, transverse colon.

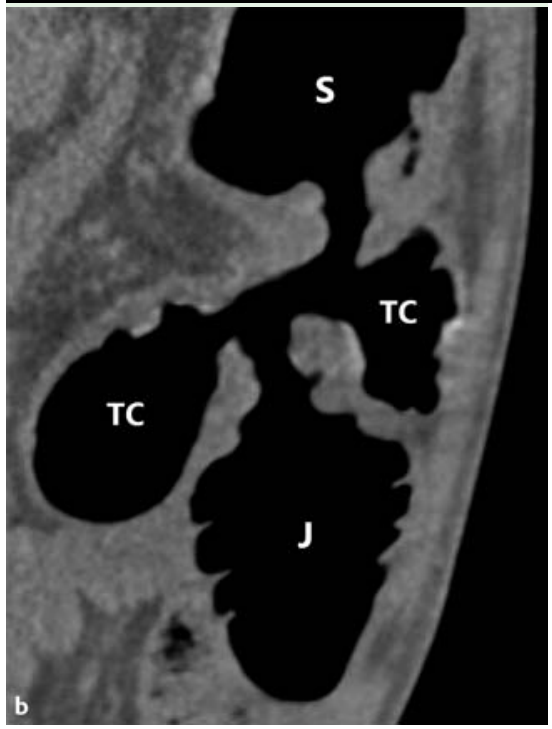

Jae Hyun Kim, Seun Ja Park, Moo In Park, Won Moon, Sung Eun Kim, Hye Jung Kwon, Youn Jung Choi

Department of Gastroenterology, Kosin University College of Medicine, Busan, Korea

\section{References}

1 Herbella FA, Del Grande JC, Beaton HL. Surgical images: soft tissue. Postgastrectomy benign gastrojejunocolic fistula. Can J Surg 2007; 50: 397-398

2 Forrest EH, McMahon A, Danesh BJ. A man with a leaky drain. Lancet 2000; 355: 1238

3 Barber KW Jr, Waugh JM, Priestley JT. Operation in one stage for gastrojejunocolic fistula. Surg Clin North Am 1962; 42: 1443-1449

4 Cody JH, DiVincenti FC, Cowick DR et al. Gastrocolic and gastrojejunocolic fistulae: report of twelve cases and review of the literature. Ann Surg 1975; 181: 376-380

\section{Bibliography}

Dol http://dx.doi.org/

10.1055/s-0034-1377210

Endoscopy 2015; 47: E333-E334

(c) Georg Thieme Verlag KG

Stuttgart · New York

ISSN 0013-726X

\section{Corresponding author}

\section{Seun Ja Park, MD}

Department of Gastroenterology Department of Internal Medicine Kosin University College of Medicine 34 Amnam-dong, Seo-gu Busan 602-702

Korea

Fax: +82-51-9905055

parksj6406@daum.net 